\title{
The Impact of Design Parameters on the Average Torque of Double-Stator Switched Flux PM Machines
}

\author{
C.C. Awah ${ }^{1}$, O.I. Okoro ${ }^{1}$ and E. Chikuni ${ }^{2}$ \\ ${ }^{1}$ Department of Electrical and Electronics Engineering, Michael Okpara University of \\ Agriculture, Umudike, Nigeria \\ ${ }^{2}$ Department of Electrical Engineering, University of Zimbabwe, Harare, Zimbabwe \\ ccawah@ieee.org, profogbonnayaokoro@ieee.org, echikuni@ieee.org
}

\begin{abstract}
The effect of main design geometries on the average torque of double-stator switched flux PM machines (DS-SFPM) is investigated in this paper. Firstly, a genetic algorithm optimization technique is employed in order to obtain the optimum design parameters of each of the investigated machine at fixed copper loss condition. Furthermore, a quantitative comparison of the different stator and rotor pole combinations is also presented. Moreover, the analyzed double-stator machines equipped with different winding topologies is also presented. The analyses are carried out with 2D-finite element (FEA) analysis software. Overall, the analyzed 14-pole machine having all-pole wound topology seems to be the most promising candidate as it exhibits the largest average torque. Above all, the predicted results show that there is optimum value of each of the leading design elements due to the saturation of the armature reaction.
\end{abstract}

Keywords: Armature reaction, design parameters, double air-gap machines, PM machines.

\section{Introduction}

Double-stator PM machines are increasingly becoming interesting research area owing to the fact that the double air-gap machines are capable of producing larger torque density than their equivalent single-stator single air-gap counterparts. However, these dual air-gap machines may possess enormous manufacturing complexity relative to their equivalent single stator PM machines. Nevertheless, its abundance advantage of larger electromagnetic torque and output power overshadows these flaws. In particular, the investigated machines in this study combine the advantages of flux-switching and flux-modulation effects in one integrated system.

A comparison of the electromagnetic performance of DS-SFPM machine is given in [1], which consists of a salient pole stator and salient pole rotor. However, the machine structure in [1] essentially consists of two independent switched flux permanent magnet (SFPM) machines, i.e. inner and outer SFPM machines respectively. Furthermore, [2] proposed a double-stator switched flux PM machine utilizing ferrite material. However, the analyzed machine in [2] has low output torque

ACRID 2017, June 20-21, Victoria Falls, Zimbabwe

Copyright $(\mathcal{2} 2017$

DOI 10.4108/eai.20-6-2017.2271002 
since ferrites are characterized by low energy density materials. Moreover, it is easily prone to demagnetization on high electric loading. The operating principle of the analyzed machines in this paper is similar to that of SFPM and magnetically-geared machines given in [3] and [4], respectively. Recently, magnetically-geared machines have been investigated extensively due to their numerous advantages as well as the need to improve and explore more of its output potentials as found in literature [5], [6], and [7]. The influence of rotor geometry on the output torque of double-stator switched reluctance machine is investigated in [8], due to the great importance of machine geometry on the overall performance of electrical machines.

The impact of main design parameters on the average torque are presented in this study. The analysis includes different stator and rotor pole number combinations, as well as different winding configurations i.e. all-pole wound and alternate-pole wound topologies. The study shows that, there is an optimum value of each of the design geometries due to the saturation effect of the electromagnetic circuit. It is worth mentioning that, the analyzed machines would be most suited for fault tolerant applications since it could be used as two separate machines i.e. dual 3-phase systems, due to the advantage of having two integrated stators.

\section{The machine topology}

Fig. 1 shows the cross-sections of the analyzed machines having different winding topology. The investigated machines are made up of U-shaped inner and outer stator with permanent magnets (PMs) sandwiched in-between the stator teeth. Note that, the PMs are circumferentially magnetized with opposite polarity placed side by side. It is worth noting that, in order to obtain the electromagnetic torque, the PMs that are placed directly opposite to each other on both stators must be of reversed polarity. Furthermore, the flux focusing technique is adopted in this analysis in order to enhance the overall flux density around the machine's airgap. The manufacturing complexity of the cup-rotor which modulates the flux is a major demerit of this type of machine.

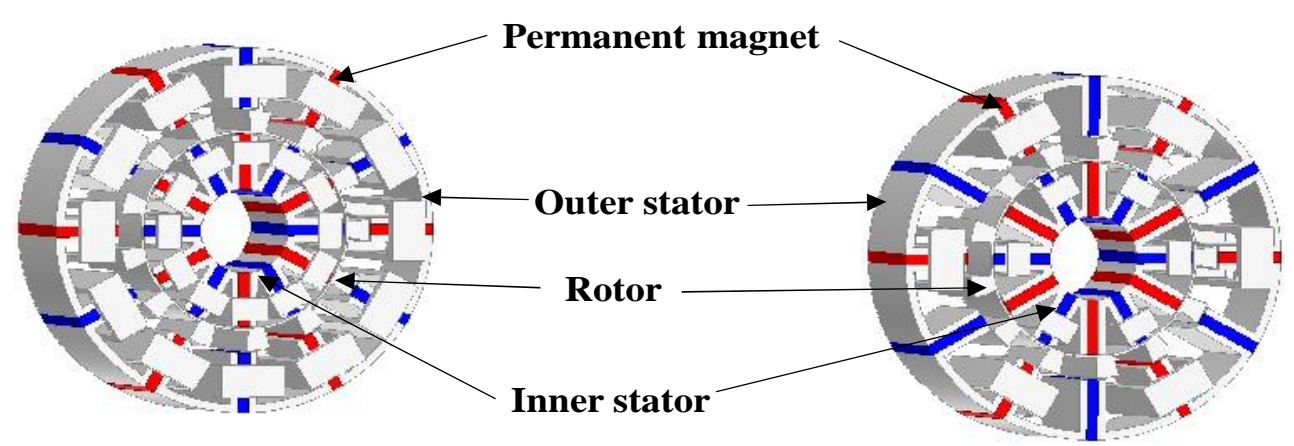

Fig. 1. Cross sections of the analyzed machines having different winding configuration. (a) All-pole-wound (b) Alternate-pole-wound. 
For ease of expression, we would represent the all-pole wound and alternate-pole wound machines in this paper as ALL-W and ALT-W, respectively. The values of the optimum design parameters are listed in Table 1.

Table 1. Parameters of the analysed machines.

\begin{tabular}{|c|c|c|c|c|c|c|c|c|}
\hline Item & & & & & alue & & & \\
\hline Machine topology & $\begin{array}{c}12 / 10 \\
\text { ALL-W }\end{array}$ & $\begin{array}{c}12 / 10 \\
\text { ALT-W }\end{array}$ & $\begin{array}{c}12 / 11 \\
\text { ALL-W }\end{array}$ & $\begin{array}{c}12 / 11 \\
\text { ALT-W }\end{array}$ & $\begin{array}{c}12 / 13 \\
\text { ALL-W }\end{array}$ & $\begin{array}{c}12 / 13 \\
\text { ALT-W }\end{array}$ & $\begin{array}{c}\text { 12/14 } \\
\text { ALL-W }\end{array}$ & $\begin{array}{c}12 / 14 \\
\text { ALT-W }\end{array}$ \\
\hline Stator pole number, $N_{s}$ & & & & & 12 & & & \\
\hline Number of phases, $m$ & & & & & 3 & & & \\
\hline $\begin{array}{l}\text { No. turns/coil (inner- } \\
\text { stator) }\end{array}$ & 6 & 12 & 6 & 12 & 6 & 12 & 6 & 12 \\
\hline $\begin{array}{l}\text { No. turns/coil (outer- } \\
\text { stator) }\end{array}$ & 12 & 24 & 12 & 24 & 12 & 24 & 12 & 24 \\
\hline $\begin{array}{l}\text { Outer stator diameter } \\
(\mathrm{mm})\end{array}$ & & & & & 90 & & & \\
\hline $\begin{array}{l}\text { Active stack length } \\
(\mathrm{mm})\end{array}$ & & & & & 25 & & & \\
\hline Split ratio & 0.58 & 0.60 & 0.61 & 0.62 & 0.66 & 0.63 & 0.64 & 0.66 \\
\hline $\begin{array}{l}\text { Rotor radial thickness } \\
(\mathrm{mm})\end{array}$ & 5.49 & 5.48 & 5.38 & 5.45 & 5.46 & 5.27 & 5.44 & 5.46 \\
\hline PM thickness (mm) & 2.83 & 2.91 & 2.88 & 2.68 & 2.63 & 2.73 & 2.67 & 2.78 \\
\hline $\begin{array}{l}\text { Outer rotor iron } \\
\text { width/pitch ratio }\end{array}$ & 0.35 & 0.34 & 0.34 & 0.37 & 0.38 & 0.37 & 0.36 & 0.36 \\
\hline $\begin{array}{l}\text { Inner rotor iron } \\
\text { width/pitch ratio }\end{array}$ & 0.41 & 0.39 & 0.37 & 0.34 & 0.31 & 0.32 & 0.31 & 0.28 \\
\hline $\begin{array}{l}\text { Back-iron thickness } \\
(\mathrm{mm})\end{array}$ & 2.22 & 2.23 & 2.01 & 2.07 & 2.04 & 2.03 & 2.08 & 2.06 \\
\hline $\begin{array}{l}\text { Stator tooth-width } \\
(\mathrm{mm})\end{array}$ & 1.7 & 1.7 & 1.7 & 1.7 & 1.7 & 1.7 & 1.7 & 1.7 \\
\hline
\end{tabular}

\section{Open circuit waveforms machine}

The phase flux-linkage of the analyzed machines is displayed in Fig. 2. We could observe that, the flux-linkage waveforms are essentially sinusoidal and symmetrical about the rotor position. The respective amplitudes of the flux linkages are: $4.65 \mathrm{mWb}$, 
$4.75 \mathrm{mWb}, 4.57 \mathrm{mWb}, 4.77 \mathrm{mWb}, 4.52 \mathrm{mWb}, 4.53 \mathrm{mWb}, 4.42 \mathrm{mWb}$ and $4.38 \mathrm{mWb}$ for each pair of the all-pole wound and alternate-pole wound topologies, of the 12/10, $12 / 11,12 / 13$ and 12/14 machines, respectively.

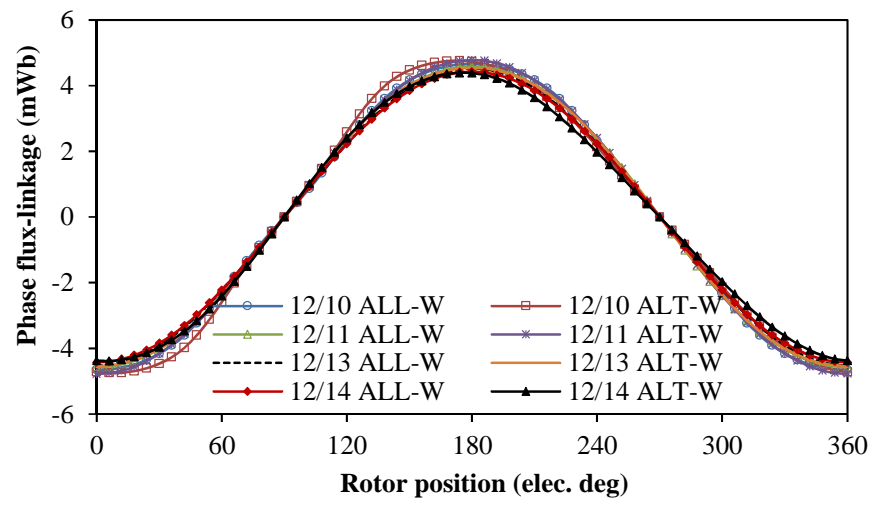

Fig. 2. Comparison open-circuit phase flux-linkage, $i_{d}=0$.

Fig. 3(a) depicts the waveforms and the corresponding spectra of the back-EMF. Although, the waveforms are symmetrical about the rotor position, they are not completely sinusoidal. This is evident in the spectra of Fig. 3(b), which implies that there could be noticeable cogging torque in the machines, which is an undesirable quality. However, the 14-rotor pole machine having all-pole wound configuration is free of this defect.

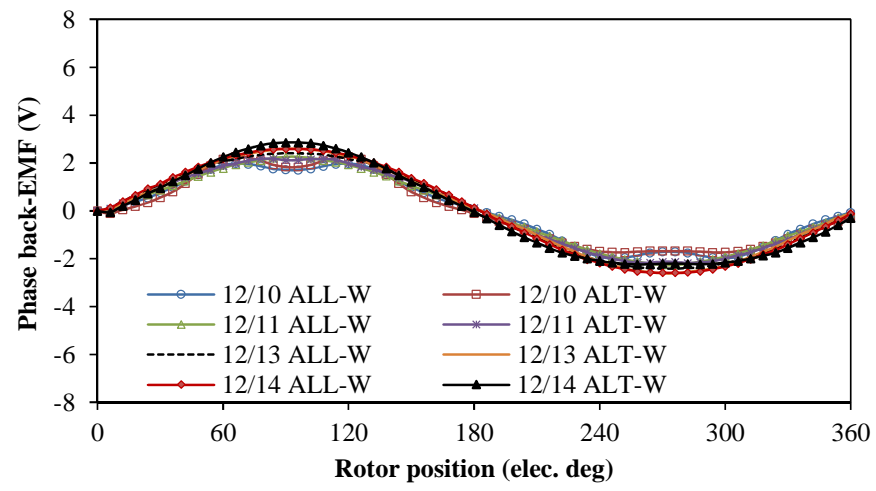

Fig. 3(a) Waveforms. 


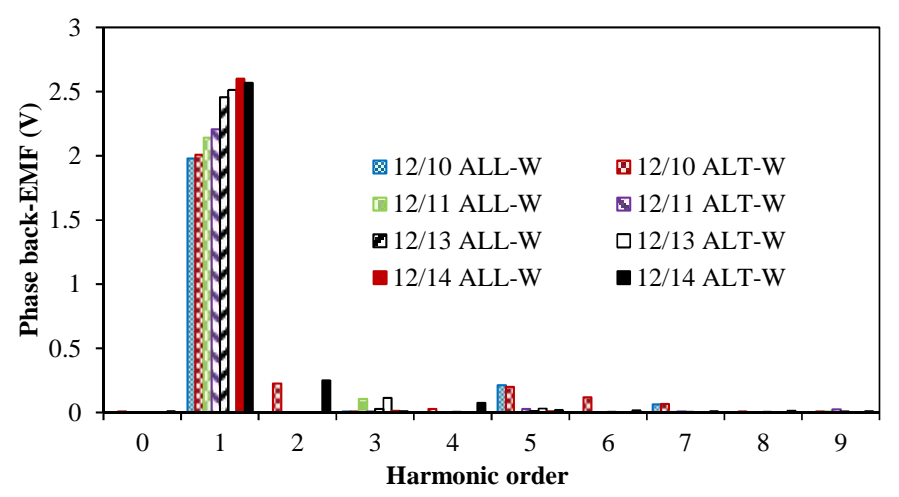

Fig. 3 (b). Comparison of phase back-EMF at 400rpm when $i_{d}=0$.

\section{Effect of leading design parameters}

It is imperative for us to investigate the impact of machine geometry on the electromagnetic torque of the analyzed machines, due to its great influence on key factors such as the torque, power, losses and efficiency of any given electrical machine. Hence, the essence of this study. The investigated design parameters include: inner and outer rotor radial lengths, the split ratio, PM thickness, rotor radial thickness, back-iron thickness and stator tooth-width. The optimum values of the machine design parameters are listed Table 1.

It is obvious from Fig. 4, that there is an optimum split ratio for each of the analyzed machines, owing to the fact that the magnetic saturation of the machines varies as the slot area changes. Thus, the split ratio is largely dependent on the available slot area for the conductors. In particular, the 14-pole machine having all-pole wound topology $\begin{array}{llllll}\text { has a } & \text { optimum } & \text { split }\end{array}$ 


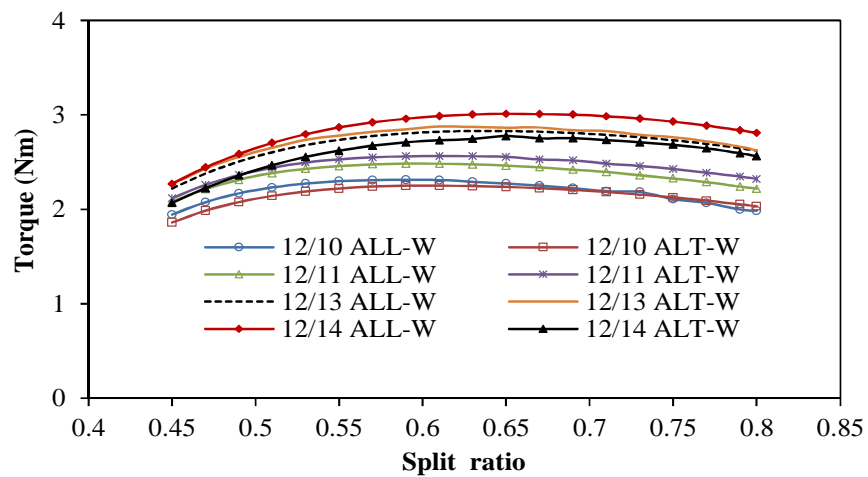

Fig. 4. Variation of average torque with split ratio, copper loss $=30 \mathrm{~W}$ and $i_{d}=0$.

The non-linearity in the change of average torque as function of the PM thickness is not significant. However, we must note that, the PM variation is limited by the shaft diameter which is fixed. The optimized values of the PM thickness are listed in Table 1.

Figure 5 shows the variation of average torque PM thickness at fixed copper loss of $30 \mathrm{~W}$ and zero $d$-axis current control.

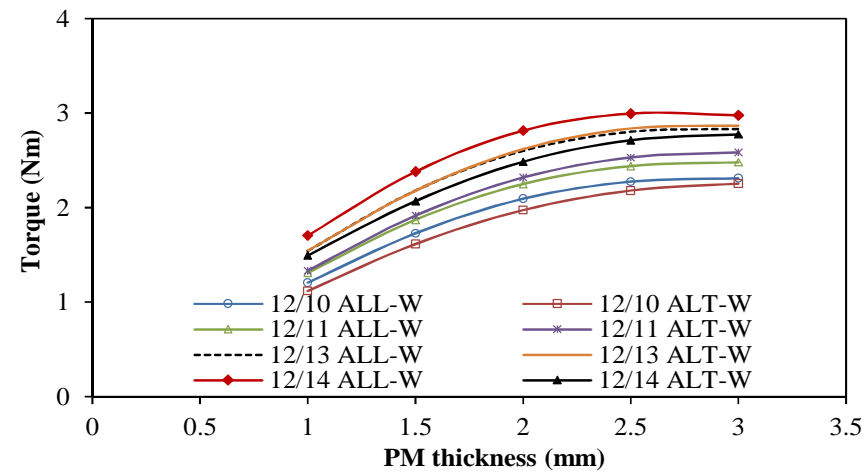

Fig. 5. Variation of average torque with PM thickness, copper loss $=30 \mathrm{~W}$ and $i_{d}=0$.

The variation of average torque with the rotor width is shown in Fig. 6. Although, there is an optimum value of the radial thickness in each case, the sensitivity of the variation is more or less linear. It is worth noting that, the smaller the rotor radial size, the easier the electromagnetic saturation on this part of the machine. Thus, the lower the output torque. Also, a very large size of the radial thickness would reduce the available space for the conductors, as well as the phase current. 


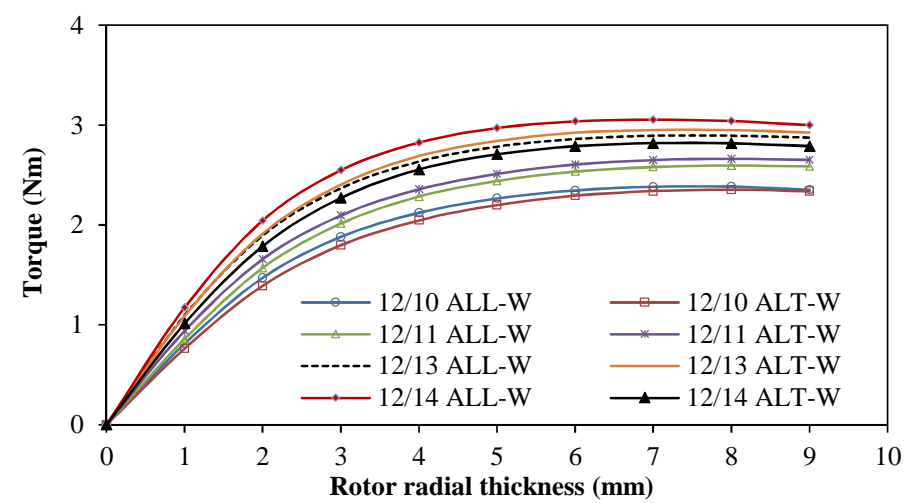

Fig. 6. Variation of average torque with rotor radial thickness, copper loss $=30 \mathrm{~W}$ and $i_{d}=0$.

Figs. 7 and 8 show the variation of average torque with the inner and outer radial lengths of the analysed machines. We could see that, there is a clear sensitivity in the variations. It is worth mentioning that, the available average torque on these radial lengths at each instance is a function of the modulated flux-linkages around the air-gap. In summary, as the radial length of the rotor increases, the flux-linkages around air-gap would continue to increase, until a point when the increased radial length would begin to act as a flux gap; thereby limiting the amount of flux that reaches the outer air-gap, which is the working air-gap of the machine. This effect, would invariably affect the induced electromotive force (EMF) and thus, the overall torque.

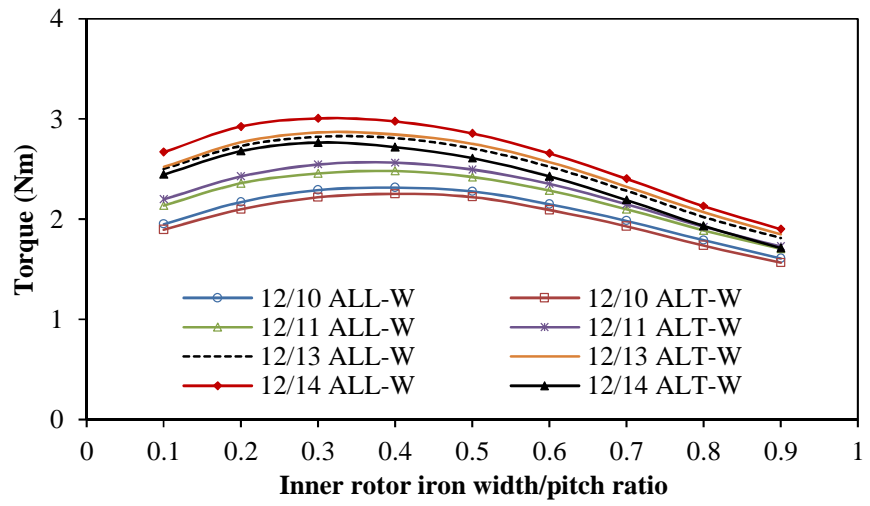

Fig. 7. Variation of average torque with inner rotor iron width/pitch ratio, copper loss $=30 \mathrm{~W}$ and $i_{d}=0$. 


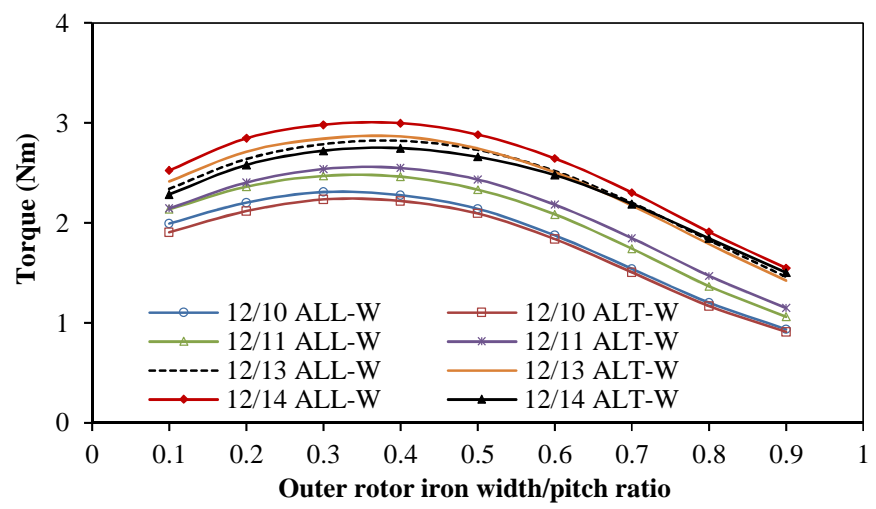

Fig. 8. Variation of average torque with outer rotor iron width/pitch ratio, copper loss $=30 \mathrm{~W}$ and $i_{d}=0$.

The average torque variation with the outer stator yoke is shown in Fig. 9. As the back-iron thickness gets thinner, it becomes easier to saturate; thus, resulting to lower output torque. Also, as the back-iron thickness enlarges, a lot of the flux-linkages could leak away due to fringing effect, thereby, leading to lower value of the average torque. Therefore, a sacrifice must be made between the stator yoke size for optimum torque production.

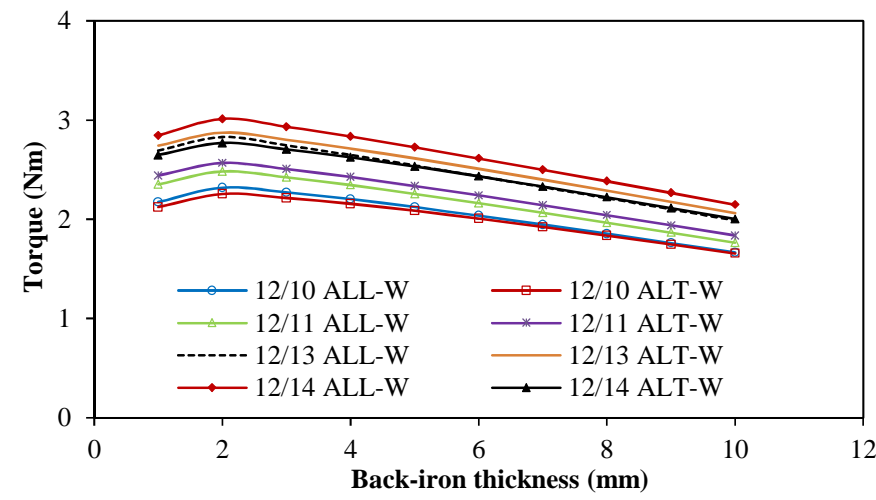

Fig. 9. Variation of average torque with back-iron thickness, copper loss $=30 \mathrm{~W}$ and $i_{d}=0$.

Fig. 10 shows the variation of average torque with the stator tooth-width. The implication of smaller tooth-width is an increased slot area for the windings, this would lead to increased phase current and hence improved output torque, since the copper loss of the machine is fixed at about $30 \mathrm{~W}$. This trend will continue until, eventually magnetic saturation sets in, due to the excessive electric load on the available thin stator-width. Similarly, a large stator-width could lead to reduced slot area; thus, a reduced output torque. Therefore, a balance is needed in order to achieve an optimum torque. 


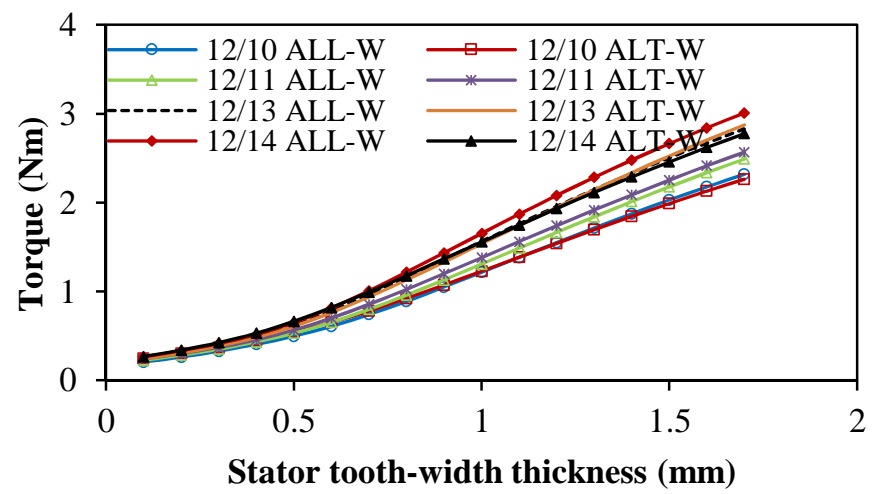

Fig. 10. Variation of average torque with stator tooth thickness, copper loss $=30 \mathrm{~W}$ and $i_{d}=0$.

\section{Conclusion}

The influence of leading design parameters on the average torque of double-stator switched flux PM machines having different winding configurations is investigated. From the analysis, it is obvious that a compromise is always made at some point as we vary the different design parameters over a range of values, due to the varying saturation effect of the armature reaction, in order to obtain the maximum average torque. Moreover, the study shows that the 14-rotor pole machine having all-pole wound topology seems to be the best candidate amongst all the investigated machines, since it produces the largest output torque under the same condition. The worst amongst the analyzed machines in terms of torque capability is the 10rotor pole machine. 


\section{References}

[1] Zaiyun, Z., Li, Q., and Zixuan, X.: Comparison of double-stator flux-switching permanent magnet machine and double-stator permanent synchronous machine for electric vehicle applications. In Proceedings International Conference on Electrical Machines and Systems, Hangzhou, China. pp. 234-239 (2014).

[2] Kim, D., Hwang, H., Bae, S., and Lee, C.: Analysis and design of double-stator flux-switching permanent magnet machine using ferrite magnet in hybrid electric vehicles. IEEE Transactions on Magnetics. pp. 8106604 (2016).

[3] Chen, J.T., and Zhu, Z.Q.: Comparison of all- and alternate-poles-wound flux-switching PM machines having different stator and rotor pole numbers. IEEE Transactions on Industry Applications. pp. 1406-1415 (2010).

[4] Awah, C.C., Zhu, Z.Q, Wu, Z., and Wu, D.: High torque density magnetically-geared switched flux permanent magnet machines. In Proceedings International Conference on Ecological Vehicles and Renewable Energies, Monaco. pp. 1-6 (2015)

[5] Liu, C.T., Chung, H.Y., and Hwang, C.C.: Design assessments of a magnetic-geared double-rotor permanent magnet generator. IEEE Transactions on Magnetics. pp. 4001004 (2014).

[6] Wang, L.L., Shen, J.X., Luk, P.C.K., Fei, W.Z., Wang, C.F., and Hao, H.: Development of a magnetic-geared permanent-magnet brushless motor. IEEE Transactions on Magnetics. pp. 45784581 (2009)

[7] Evans, D.J., and Zhu, Z.Q.: Novel partitioned stator switched flux permanent magnet machines. IEEE Transactions on Magnetics. pp. 8100114 (2015).

[8] Wang, W., Luo, M., Cosoroaba, E., Fahimi, B., and Kiani, M.: Rotor shape investigation and optimization of double stator switched reluctance machine. IEEE Transactions on Magnetics. pp 8103304 (2015). 